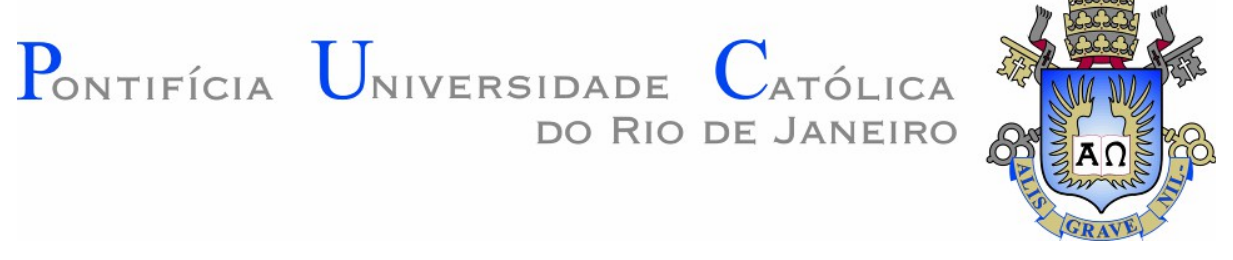

Igor de Oliveira Costa

\title{
Verbos meteorológicos no plural em orações relativas do Português Brasileiro: sintaxe e processamento
}

Dissertação de Mestrado

Dissertação apresentada ao Programa de Pós-Graduação em Estudos da Linguagem da PUC-Rio como requisito parcial para obtenção do título de mestre em Letras/Estudos da Linguagem.

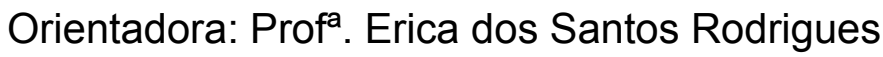

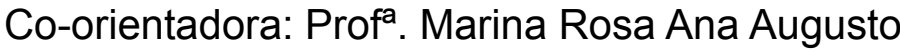

Rio de Janeiro, Dezembro de 2013 


\section{Igor de Oliveira Costa}

\section{Verbos meteorológicos no plural em orações relativas do Português Brasileiro: sintaxe e processamento}

Dissertação apresentada como requisito parcial para obtenção do grau de Mestre pelo Programa de Pós-Graduação em Estudos da Linguagem do Departamento de Letras do Centro de Teologia e Ciências Humanas da PUCRio. Aprovada pela Comissão Examinadora abaixo assinada.

Profa. Erica dos Santos Rodrigues

Orientadora

Departamento de Letras - PUC-Rio

Profa. Marina Rosa Ana Augusto

Co-Orientadora

UERJ

Profa. Letícia Maria Sicuro Corrêa

Departamento de Letras - PUC-Rio

Profa. Maria Eugenia Lammoglia Duarte

Profa. Denise Berruezo Portinari Coordenadora Setorial do Centro de Teologia e Ciências Humanas - PUC-Rio 
Todos os direitos reservados. É proibida a reprodução total ou parcial do trabalho sem autorização do autor, do orientador e da universidade.

\section{Igor de Oliveira Costa}

Graduou-se em Letras: Português/Literaturas pela Universidade do Estado do Rio de Janeiro (UERJ) em 2010.

Ficha Catalográfica

Costa, Igor de Oliveira

Verbos meteorológicos no plural em orações relativas do português brasileiro : sintaxe e processamento / Igor de Oliveira Costa ; orientadora: Erica dos Santos Rodrigues ; co-orientadora: Marina Rosa Ana Augusto. - 2013.

196 f. : il. (color.) ; $30 \mathrm{~cm}$

Dissertação (mestrado) - Pontifícia Universidade Católica do Rio de Janeiro, Departamento de Letras, 2013.

Inclui bibliografia

1. Letras - Teses. 2. Verbos meteorológicos. 3. Orações relativas. 4. Tópicos locativos. 5. Concordância. 6. Processamento de sentenças. I. Rodrigues, Erica dos Santos. II. Augusto, Marina Rosa Ana. III. Pontifícia Universidade Católica do Rio de Janeiro. Departamento de Letras. IV. Título.

CDD: 400 
Às minhas duas mães,

Maria do Carmo e Maria Irene, sem as quais eu não seria 


\section{Agradecimentos}

A meus amigos e parentes, pelo apoio, especialmente àqueles que muito me incentivaram nessa jornada acadêmica e me apoiaram nos momentos difíceis da vida. Saibam todos que esta pessoa não teria sido possível sem vocês.

A meus professores da UERJ e da PUC-Rio, especialmente àqueles que despertam em nós o amor que sentem pelo que ensinam. Saibam todos que este aluno não teria sido possível sem vocês.

A minhas orientadoras, pelo rigor intelectual, pelo profissionalismo, pela integridade, pela orientação segura e por aturarem meus atrasos e crises existenciais. Saibam ambas que este trabalho não seria possível sem vocês.

A todas as pessoas que se voluntariaram a participar dos experimentos.

Ao CNPq e à PUC-Rio, ,pelos auxílios concedidos, sem os quais este trabalho não poderia ter sido realizado. 


\section{Resumo}

Costa, Igor de Oliveira; Rodrigues, Erica dos Santos (orientadora); Augusto, Marina Rosa Ana (co-orientadora). Verbos meteorológicos no plural em orações relativas do Português Brasileiro: sintaxe e processamento. Rio de Janeiro: 2013. 196p. Dissertação de Mestrado - Departamento de Letras, Pontifícia Universidade Católica do Rio de Janeiro.

Esta dissertação aborda um fenômeno pouco estudado do Português Brasileiro (PB): o caso dos verbos meteorológicos (v.g. chover, ventar, nevar, trovejar) flexionados no plural em aparente concordância com um tópico de natureza locativa/temporal, especialmente em contextos sintáticos de orações relativas. Esses verbos são investigados à luz de uma proposta de integração entre a teoria linguística de vertente gerativista e modelos procedimentais de natureza serial, a qual tem caracterizado as pesquisas desenvolvidas no Laboratório de Psicolinguística e Aquisição da Linguagem da PUC-Rio (LAPAL). A concordância entre sujeito e verbo é um processo robusto nas línguas naturais e a não compatibilidade entre as marcas de número desses elementos é comumente associada, nas pesquisas que abordam o assunto, aos chamados lapsos de concordância. A fim de investigar se verbos plurais nessas estruturas não passam de instâncias encontradas ao acaso, foram inicialmente, realizados, em ambiente controlado, dois experimentos: um de produção eliciada e um de compreensão envolvendo leitura automonitorada. Os resultados indicam (i) que verbos meteorológicos no plural, quando em orações relativas cortadoras, são efetivamente produzidos por falantes de PB; e (ii) que os falantes de PB não são sensíveis, na compreensão, a tais marcas plurais, num indicativo de que a concordância entre verbo e um locativo/temporal faria parte da gramática da língua, não se configurando como lapso de concordância. Lapsos, segundo resultados do experimento de produção eliciada, poderiam ser postulados apenas para o caso das sentenças relativas padrão. Propostas gerativistas para a caracterização da gramática do PB são consideradas a fim de se prover, a partir delas, uma análise integrada que possa explicar o fenômeno sob investigação. Essa análise é compatível com os resultados de um terceiro experimento, de julgamento de gramaticalidade em tarefa de leitura automonitorada. Verificou-se a taxa de aceitabilidade para verbos meteorológicos no singular e no plural, contrastada a de outros três tipos de verbos (inergativos, inacusativos monoargumentais e inacusativos biargumentais), sempre em orações relativas 
cortadoras. Os resultados indicam que os verbos meteorológicos se distinguem dos verbos inergativos (que não aceitam concordância com o tópico locativo/temporal) e se aproximam dos verbos inacusativos (que efetivamente licenciam a concordância com tópico). Os lapsos associados a relativas padrão e a concordância com verbos meteorológicos em relativas cortadoras são explicados à luz do Modelo Integrado da Computação On-Line (MINC), desenvolvido no âmbito das pesquisas do LAPAL. Considera-se que a concordância dos verbos meteorológicos com tópico faria parte da gramática inovadora do $\mathrm{PB}$, podendo-se explicar os resultados experimentais segundo a noção de uma gramática nuclear na qual haveria uma periferia marcada.

\section{Palavras-chave}

Verbos meteorológicos; orações relativas; tópicos locativos; concordância; processamento de sentenças 


\section{Abstract}

Costa, Igor de Oliveira; Rodrigues, Erica dos Santos (Advisor); Augusto, Marina Rosa Ana (Co-advisor). Plural climate verbs in Brazilian Portuguese relative clauses: syntax and processing. Rio de Janeiro: 2013. 196p. Msc. Dissertation - Departamento de Letras, Pontifícia Universidade Católica do Rio de Janeiro.

This dissertation addresses a recently attested phenomenon in Brazilian Portuguese (BP): plural agreement between climate verbs (v.g. chover, ventar, nevar, trovejar) and locative/temporal topics within relative clauses. This phenomenon is investigated in the light of a proposal that aims at integrating generative linguistics and psycholinguistics procedural models, a line of investigation that has characterized the research developed at the Laboratory of Psycholinguistics and Language Acquisition at PUC-Rio (LAPAL). Subject-verb agreement is a robust process in natural languages and failures in the implementation of agreement have been treated in the psycholinguistics literature in terms of speech errors, not related to grammar knowledge. In order to investigate if agreement with climate verbs is occasional or licensed by the rules of BP, two experiments were initially conducted: an elicited production study and a self-paced reading test. The results indicate that (i) speakers really produce plural climate verbs in the context of relative clauses and (ii) the BP speakers accept the occurrence of these verbs in the plural within relative clauses (specially within non-standard relatives), what favors analysing it as a grammar option and not a mere speech error. Generative proposals are considered in order to provide an integrated analysis that can explain the phenomenon under investigation. This analysis seems to be consistent with the results of a grammaticality judgment task realized as part of a self-paced reading experiment. The rate of acceptability for climate verbs in the singular and plural has been contrasted to the rate of other three types of verbs (unergative, monoargumental and biargumental unaccusative verbs), always in the context of relative clauses. The results indicate that climate verbs differ from unergative ones (which will not allow agreement with locative / temporal topics) and are similar to unaccusative verbs (which effectively license agreement with a topic). The results are explained in the light of an Integrated Model of On-Line Computation (MINC). It is considered that plural agreement of climate verbs with a topic would be compatible to the notion of a core grammar 
with a marked periphery, characterizing an innovative BP grammar.

\section{Keywords}

Climate verbs; relative clauses; locative topics; agreement; sentence processing 


\section{Sumário}

1. Introdução

2. Modelos de processamento da concordância 24

2.1. Processamento da concordância na produção 26

2.1.1. Visão geral do modelo de produção 26

2.1.2. Codificação gramatical: modelos lexicalistas versus $\begin{array}{ll}\text { modelo gerativista } & 31\end{array}$

2.1.2.1. Modelos de Levelt (1989 e 1999) \& Bock \& Levelt (1994) 32

2.1.2.1.1. A concordância segundo o modelo de cópia de traços 35

2.1.2.1.2. A concordância segundo o modelo de unificação de traços

2.1.2.1.3. A concordância segundo o Modelo de Recuperação na Memória de Trabalho 39

2.1.2.2 O modelo de Produção Monitorada por Parser (PMP) 41

2.1.2.3. Computação da concordância em orações relativas 43

2.2. Processamento da concordância na compreensão 44

2.2.1. Visão geral da compreensão 44

2.2.2. A computação da concordância na compreensão e a percepção do erro 45

2.2.3. Alguns estudos sobre a computação da $\begin{array}{ll}\text { concordância na compreensão } & 47\end{array}$

2.3. Conclusões 52

3. Primeiros resultados experimentais 54

3.1. Experimento 1: produção oral induzida 54

3.2. Experimento 2: Leitura automonitorada 64 
4. Aspectos da sintaxe do Português Brasileiro 72

4.1. O parâmetro do sujeito nulo 73

4.1.1. sujeitos não referenciais preenchidos $\quad 77$

4.1.2. Sujeitos expletivos e verbos meteorológicos 80

4.1.3. Resumo da seção 4.1

4.2. Português Brasileiro como língua de tópico 84

4.2.1. O tópico e o empobrecimento flexional do PB 85

4.2.2. Concordância com tópico: características do tópico-sujeito 86

4.2.3. Tópico-sujeito: Pessoa como categoria independente 88

4.2.4. Tópicos e concordância no caso dos verbos meteorológicos 90

4.2.4.1. Pronomes pessoais sujeitos de verbos meteorológicos? 90

4.2.4.2. O problema da concordância: primeira abordagem 94

4.2.5. Resumo da seção 4.2

4.3. Locativos pré-verbais obrigatórios 96

4.3.1. Inversão locativa e posição de sujeito 99

4.3.2. Locativos-temporais em sentenças com verbos meteorológicos 101

4.3.3. Resumo da seção $4.3 \quad 105$

4.4. A natureza do EPP de Tense e a Hipótese da Inacusatividade Biargumental 106

4.4.1. A concordância no casos dos verbos meteorológicos 109

4.4.2. A hipótese da inacusatividade biargumental 111

4.4.2.1. Verbos meteorológicos e a hipótese da inacusatividade biargumental 114

4.4.3. Resumo da seção $4.4 \quad 115$

4.5. As orações relativas não padrão do PB 116

4.5.1. O modelo Raising de geração de relativas 118

4.5.2. A geração de relativas não padrão do PB 120

4.5.3. Verbos meteorológicos em orações relativas 122

4.5.4. Resumo da seção 4.5

4.6. Conclusões 124 
5. Julgamento de gramaticalidade

5.1. Experimento 3: Julgamento de gramaticalidade

e leitura automonitorada

126

5.2. Conclusões

6. Derivando sentenças com verbos meteorológicos no MINC

6.1. Modelo Integrado da Computação On-Line (MINC) 135

6.1.1. A formulação sintática segundo o MINC 137

6.2. Derivando relativas com verbos meteorológicos no MINC

6.2.1. Derivando uma relativa cortadora com verbo meteorológico plural - Produção

6.2.3. Derivando uma relativa cortadora com verbo meteorológico plural - Compreensão 143

6.3. Lapsos de concordância segundo o MINC

6.3.1. Derivando uma relativa padrão com verbo meteorológico plural na produção - o caso dos lapsos de concordância

6.4. Relativas cortadoras no singular e os falantes diglóssicos do PB

6.4.1. Derivando uma relativa cortadora com verbo meteorológico singular na produção

6.4.2. Verbos meteorológicos no PB e falantes diglóssicos 151

6.5. Conclusões

7. Conclusão

Referências bibliográficas

Apêndice: A crítica de Clarke (1973): a língua como um efeito fixo

Anexo 1: Dados anedóticos 


\section{Lista de figuras}

Figura 1: Etapas e subetapas da produção da fala, segundo Levelt (1989, 1999)

Figura 2: Esquema do modelo de cópia de traços 36

Figura 3: Esquema do modelo de unificação de traços 38

Figura 4: Hierarquia Referencial (Cyrino, Duarte \& Kato, 2000;

Kato et al., 2006; Duarte, 2012: 12)

Figura 5: Representação esquemática da direcionalidade mista da derivação

Figura 6: Representação esquemática de derivação: exemplo 1

Figura 7: Representação esquemática de derivação: exemplo 2138

Figura 8: Representação esquemática de derivação: exemplo 3138

Figura 9: Representação esquemática de derivação: exemplo $4 \quad 141$

Figura 10: Representação esquemática de derivação: exemplo 5141

Figura 11: Representação esquemática de derivação: exemplo 6142

Figura 12: Representação esquemática de derivação: exemplo 7142

Figura 13: Representação esquemática de derivação: exemplo $8 \quad 147$ 


\section{Lista de gráficos}

Gráfico 1: Experimento 1 - Sistematicidade intraindividual na produção de verbos no singular e no plural - condições com antecedente do tipo NP

Gráfico 2: Experimento 1 - Sistematicidade intraindividual na produção de verbos no singular e no plural - condições com antecedente do tipo PP

Gráfico 3: Experimento 2 - Tempos Médios de Reação (RT) em milisegundos (painel à esquerda do leitor) e logaritmo de RT (painel à direita) para as posições do verbo e do advérbio final. Barras verticais indicam o erro padrão de cada média Gráfico 4: Experimento 2 - Efeito não significativo na posição do verbo (painel à esquerda do leitor) e significativo de interação entre o tipo de antecedente e a flexão de número do verbo (painel à direita). Barras verticais indicam o erro padrão das médias Gráfico 5 : Experimento 3 - Porcentagem de julgamentos SIM por condição 


\section{Lista de tabelas}

Tabela 1: Frequência de lapsos de concordância em experimentos da literatura psicolinguística

Tabela 2: Exemplos de estímulos experimentais para condições do experimento 1

Tabela 3: Experimento 1 - Quantidade de verbos meteorológicos no plural e no singular para cada condição experimental

Tabela 4: Experimento 1 - Valores estimados por regressão logística de efeitos mistos

Tabela 5: Experimento 1 - Valores estimados por regressão logística para contrastes de Tukey (pairwise)

Tabela 6: Experimento 1 - Quantidade de verbos meteorológicos no plural em função do tipo de relativa efetivamente produzido

Tabela 7: Experimento 1 - Valores estimados por regressão logística de efeitos mistos para relativas efetivamente produzidas

Tabela 8: Valores estimados por regressão logística para contrastes de Tukey (pairwise)

Tabela 9: Exemplos de estímulos experimentais do experimento de leitura automonitorada

Tabela 10: Experimento 2 - Análises de Variância pelo método F1 x $\mathrm{F} 2$ e min- $\mathrm{F}^{\prime}$

Tabela 11: Experimento 2 - Modelos lineares de efeitos mistos com interação entre tipo de antecedente e flexão de número do verbo (efeitos fixos) e interceptos para sujeitos e itens (efeitos aleatórios)

Tabela 12: Experimento 2 - Valores estimados por regressão logística para contrastes de Tukey (pairwise) 
Tabela 13: Experimento 3 - Exemplos de estímulos experimentais para cada uma das condições

Tabela 14: Experimento 3 - Distribuição dos itens experimentais pelos grupos

Tabela 15: Resultados significativos de regressão logística de efeitos mistos aplicada aos dados experimentais 
...um linguista não deve ser desviado de sua investigação das causas pela complexidade dos problemas

Weinreich, Labov \& Herzog

In God we trust. All others must bring data. William Edwards Deming 